\title{
Controllable Synthesis of Biocompatible Fluorescent Carbon Dots From Cellulose Hydrogel for the Specific Detection of $\mathrm{Hg}^{2+}$
}

\author{
Hailong Huang, Hao Ge, Zhipeng Ren, Zhijian Huang, Min Xu* and Xianghui Wang* \\ School of Physics and Electronic Science \& Shanghai Key Laboratory of Magnetic Resonance, East China Normal \\ University, Shanghai, China
}

OPEN ACCESS

Edited by:

Muhammad Wajid Ullah, Huazhong University of Science and Technology, China

Reviewed by:

Rajendra Kumar Singh Institute of Tissue Regeneration Engineering (ITREN), South Korea

PaYaM ZarrinTaj, Oklahoma State University, United States

${ }^{*}$ Correspondence: $\operatorname{Min} X u$ xumin@phy.ecnu.edu.cn Xianghui Wang

xhwang@phy.ecnu.edu.cn

Specialty section:

This article was submitted to Biomaterials,

a section of the journal Frontiers in Bioengineering and Biotechnology

Received: 14 October 2020 Accepted: 04 January 2021

Published: 28 January 2021

Citation:

Huang H, Ge H, Ren Z, Huang Z, $X u M$ and Wang X (2021) Controllable

Synthesis of Biocompatible

Fluorescent Carbon Dots From Cellulose Hydrogel for the Specific Detection of $\mathrm{Hg}^{2+}$. Front. Bioeng. Biotechnol. 9:617097. doi: 10.3389/fbioe.2021.617097
Heavy metal ions overload can seriously harm human health. Simple and effective strategies for the specific detection of heavy metal ions are of great important. In this work, using different pretreatment methods, a series of carbon dots (CDs) with different particle sizes and doped with varying amounts of elements $(\mathrm{O}, \mathrm{N}, \mathrm{S})$ were prepared based on the natural polymer, cellulose hydrogel. The CDs exhibit excellent fluorescence and biocompatibility. When the particle size decreased from 8.72 to $2.11 \mathrm{~nm}$, the fluorescence quantum yield increased from 0.029 to 0.183 . In addition, doping with elements $(\mathrm{N})$ also effectively enhanced the fluorescent performance of the CDs. The fluorescence of the CDs, especially for the smallest, CD-4a, was significantly quenched in the presence of the heavy metal ion, $\mathrm{Hg}^{2+}$. Thus, CD-4a may be used as a fluorescence sensor for the detection of $\mathrm{Hg}^{2+}$. The fluorescence intensity of CD4a exhibited a two-stage, concentration-dependent fluorescence response in the range 0.2-10 and 10-100 $\mu \mathrm{mol} / \mathrm{L} \mathrm{Hg}^{2+}$, with each stage having different slopes; the detection limit was $0.2 \mu \mathrm{M}$. More importantly, even in the presence of interfering metal ions, the detection of $\mathrm{Hg}^{2+}$ using the CDs-4a remained stable. Therefore, these biocompatible CDs may serve as a promising candidate for the specific detection of $\mathrm{Hg}^{2+}$.

Keywords: carbon dots, cellulose hydrogel, $\mathrm{Hg}^{2+}$ detection, fluorescent sensor, biocompatibility

\section{INTRODUCTION}

With the development of industrialization, the pollution of the environment with heavy metal ions has become a serious concern all over the world. Heavy metal ions not only harm living organisms in water, but also affect the health of humans (Lu et al., 2018; Bolisetty et al., 2019; Sarma et al., 2019; Wu et al., 2019). The overloading of heavy metal ions such as $\mathrm{Cu}^{2+}, \mathrm{Fe}^{3+}, \mathrm{Pb}^{2+}$, and $\mathrm{Hg}^{2+}$ is highly toxic to biological organisms and causes irreversible, dangerous oxidative stress and serious damage to the central nervous system leading to renal and neural problems (Ali and Khan, 2018; Kahlon et al., 2018; Cai et al., 2019; Kumar et al., 2020; Oliveira et al., 2020; Rossini-Oliva et al., 2020). During last few decades, many methods have been developed to detect heavy metal ions in water, such as inductively coupled plasma atomic emission spectroscopy (ICP-AES), X-ray absorption spectroscopy (XAS), atomic absorption spectroscopy and so on. These methods have been widely applied in the laboratory and have excellent limits of detection and provide accurate quantifications. 
However, these methods do not meet the requirements for the simple and fast detection of metals in practical applications due to the complex sample preparation, high cost of instrumentation and complex analyses (Li et al., 2016; Bansod et al., 2017; Malik et al., 2019; Qi et al., 2020). Thus, an efficient, simple and sensitive method to detect and quantify heavy metal ions in aqueous media remains a challenge in environmental detection applications.

Carbon dots (CDs) are considered an ideal fluorescent material and have received significant attention as a result of their stable fluorescence, high optical absorptivity, good physicochemical stability, and biocompatibility; furthermore, they have been widely applied in medical diagnosis, bio-imaging, sensing, photocatalysis, optoelectronic devices and full-color displays (Sharma et al., 2017; Liu et al., 2019; Meng et al., 2019; Patel et al., 2019; Zhou et al., 2019). Recently, based on the fluorescence quenching effect caused by interactions between metal ions and the fluorophore functional groups, CDs have been demonstrated to be a promising fluorescent sensor for the detection of heavy metal ions, due to the unique dimensions and functional structure (Pang et al., 2017; Ansi and Renuka, 2019; Yarur et al., 2019; Yoo et al., 2019). Wang et al. (2015) used an acidic ionic liquid $\left(\mathrm{SO}_{3} \mathrm{H}-\mathrm{IL}\right)$ as a catalyst and an ionic liquid $([\mathrm{Bmim}] \mathrm{Cl})$ as a solvent to prepare CDs from microcrystalline cellulose. The CDs exhibited excellent, selective detection of $\mathrm{Hg}^{2+}$ along with good water dispersibility and photostability. In the concentration range 6-80 $\mu \mathrm{mol} / \mathrm{L}$, it was demonstrated that the CDs were an effective fluorescent sensor for the selective quantification of $\mathrm{Hg}^{2+}$, exhibiting a good linear relationship. Wang et al. (2019) also reported a simple hydrothermal method to synthesize nitrogen-doped CDs using an ethanolamine ionic liquid (1-carboxyethyl-3methyl imidazole chloride) gel as a precursor. Due to the strong interactions between the metal ions and the surface groups and nitrogen atoms of the CDs, the CDs displayed significant heavy metal ion quenching ability for $\mathrm{Hg}^{2+}$ and $\mathrm{Cu}^{2+}$, as well as sensitive detection properties. Wu et al. (2017) summarized the relationship between the fluorescence quenching effect and the precursors and methods used. They found that, the chemically doped element $(\mathrm{O}, \mathrm{N}, \mathrm{S})$, particle size and solvatochromic effects effectively controlled not only the fluorescence performance and specific detection ability of the CDs, but also endowed the CDs with excellent heavy metal detection abilities. Their results may provide a theoretical basis from which to develop novel and improved fluorescence performance.

Although these studies (Sharma et al., 2017; Ansi and Renuka, 2019; Liu et al., 2019; Meng et al., 2019; Wang et al., 2019; Yarur et al., 2019; Zhou et al., 2019) have achieved significant progress in the development of biocompatible CDs for heavy metal ion detection, most require toxic precursors and reagents,

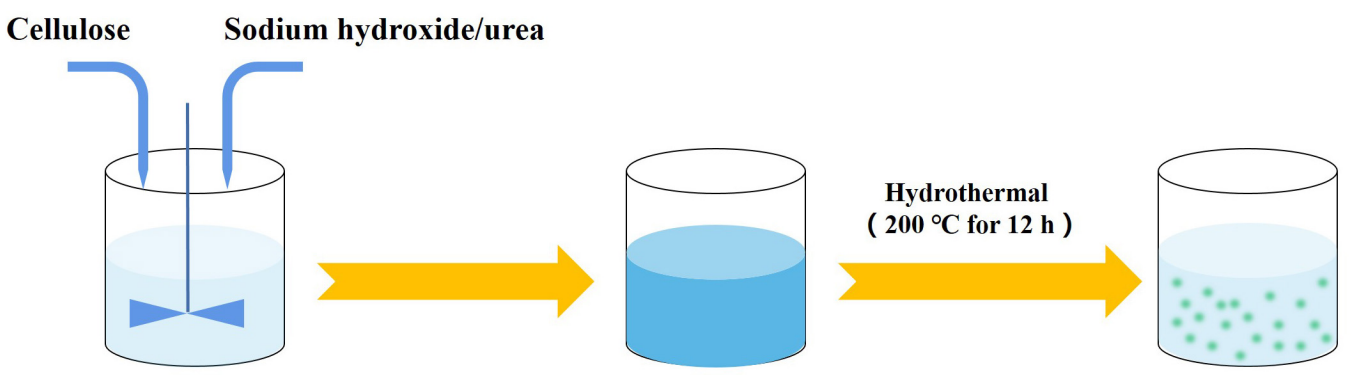

\section{Cellulose solution}

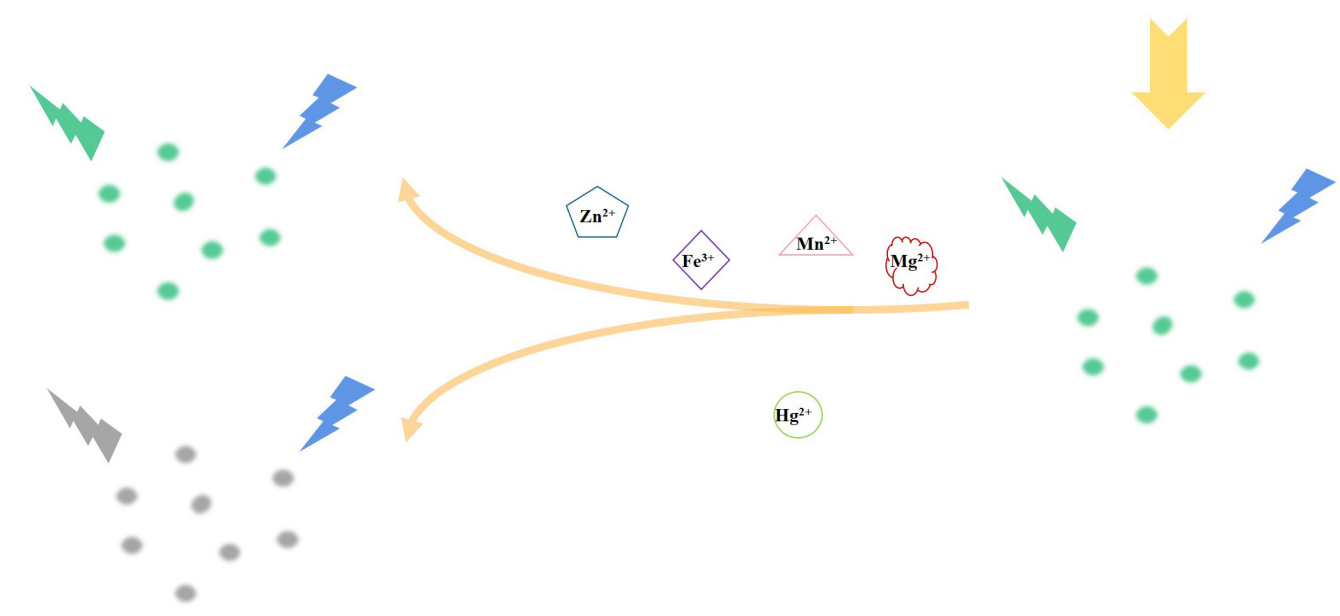

Cellulose Hydrogel

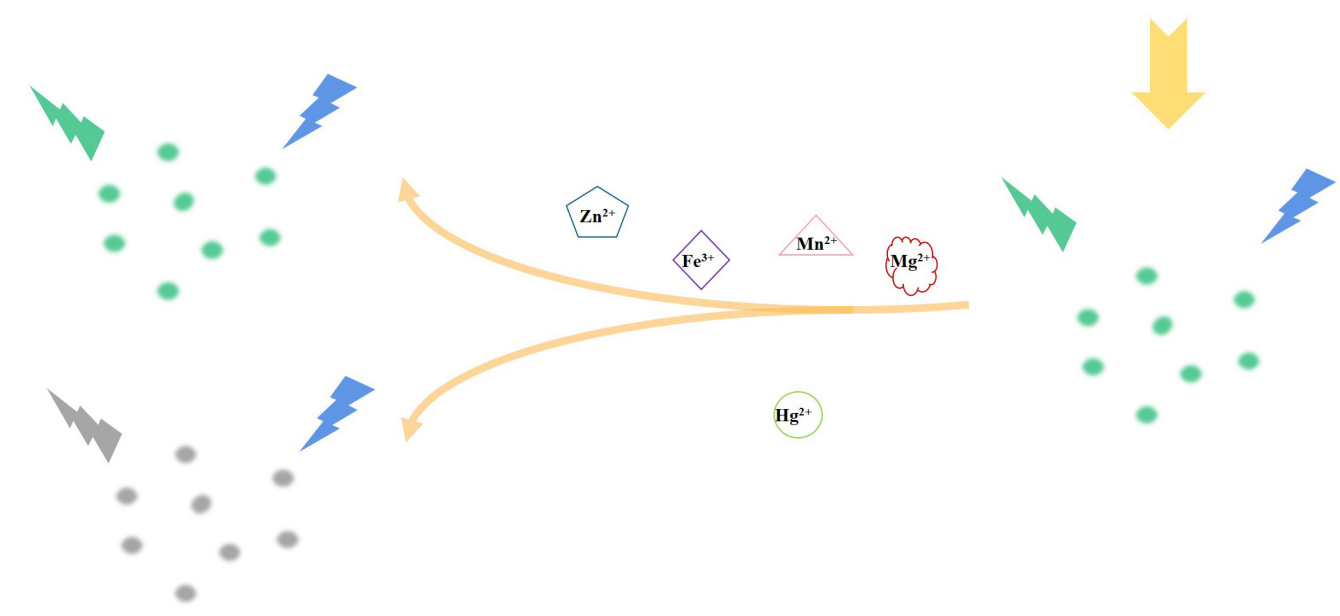

\section{Hydrogel-CDs}

SCHEME 1| Synthetic procedure and mechanism of the sensing of CDs. 
TABLE 1 | Samples name of CDs with different treatment.

\begin{tabular}{llll}
\hline & \multicolumn{3}{c}{ Molecular weight cut-off (k) } \\
\cline { 2 - 3 } Pre-treatment & $<\mathbf{1 . 2}$ & $\mathbf{1 . 2 - 1 0}$ & $>\mathbf{1 0}$ \\
\hline CDs from pure hydrogel without pre-treatment & CDs-1a & CDs-1b & CDs-1c \\
CDs from NaOH pre-treated hydrogel & CDs-2a CDs-2b & CDs-2c \\
CDs from urea pre-treated hydrogel & CDs-3a CDs-3b & CDs-3c \\
CDs from NaOH/urea pre-treated hydrogel & CDs-4a CDs-4b & CDs-4c
\end{tabular}

and expensive or complex preparation methods, especially when modifying the functional groups of CDs. The simultaneous satisfaction of these requirements remains highly challenging. Therefore, the development of a simple and effective strategy to design biocompatible CDs with sensing properties specific to the detection of heavy metal ions is necessary.

Herein, we report a simple strategy to develop biocompatible CDs based on a low-cost and natural polymer, cellulose hydrogel via a hydrothermal reaction. The prepared CDs4a exhibited excellent fluorescence performance and good biocompatibility due to the small particle size and the functional groups on the particle surface, which could be used for labeling in living cells. Based on complexion between the metal ions and the functional groups of CDs-4a, the CDs4a demonstrated the highly sensitive and specific detection of $\mathrm{Hg}^{2+}$ (Scheme 1). The CDs-4a maintained an excellent detection ability even in a complex solution containing various heavy metal ions.

\section{MATERIALS AND METHODS}

\section{Materials}

Linter Cellulose $\left(\mathrm{M}_{w}=8 \times 10^{4}\right)$ was provided by Hubei Chemical Fiber Group Co. Ltd. Epichlorohydrin (ECH), sodium hydroxide $(\mathrm{NaOH})$, urea, copper sulfate $\left(\mathrm{CuSO}_{4}\right)$, mercury nitrate $\left(\mathrm{Hg}\left(\mathrm{NO}_{3}\right)_{2}\right)$, silver nitrate $\left(\mathrm{AgNO}_{3}\right)$, manganese nitrate $\left[\mathrm{Mn}\left(\mathrm{NO}_{3}\right)_{2}\right]$, chromium nitrate $\left[\mathrm{Cr}\left(\mathrm{NO}_{3}\right)_{3}\right]$, lead nitrate $\left[\mathrm{Pb}\left(\mathrm{NO}_{3}\right)_{2}\right]$, copper chloride $\left(\mathrm{CuCl}_{2}\right)$, ferric chloride $\left(\mathrm{FeCl}_{3}\right)$, calcium chloride $\left(\mathrm{CaCl}_{2}\right)$, nickel chloride $\left(\mathrm{NiCl}_{2}\right)$, cobalt chloride $\left(\mathrm{CoCl}_{2}\right)$, zinc chloride $\left(\mathrm{ZnCl}_{2}\right)$, and magnesium chloride $\left(\mathrm{MgCl}_{2}\right)$ were purchased from Sinopharm Group, Shanghai, China. All reagents were of analytical reagent grade, and all chemicals were used without further purification.

\section{Preparation of CDs}

Linter cellulose $(4 \mathrm{~g})$ was dissolved in a pre-cooled $\left(-12^{\circ} \mathrm{C}\right)$ $\mathrm{NaOH} /$ urea aqueous solution $(7 / 12 \mathrm{wt} \%, 100 \mathrm{~g})$ to obtain the cellulose solution (Huang et al., 2016). Then, an amount of $\mathrm{ECH}(0.3 \mathrm{wt} \%)$ was added into the $4.5 \mathrm{~g}$ cellulose solution as crosslinking agent and stirred for $30 \mathrm{~min}$ at room temperature. Next, the homogeneous mixture was heated in the oven at $60^{\circ} \mathrm{C}$ for $4 \mathrm{~h}$ to obtain a uniform and transparent chemically crosslinked hydrogel. Finally, the hydrogel was soaked in deionized water for $48 \mathrm{~h}$ to completely remove the unreacted reagents from the pure cellulose hydrogel.

The pure cellulose hydrogel was placed in a hydrothermal reactor and heated at $200^{\circ} \mathrm{C}$ for $12 \mathrm{~h}$. Then, the crude CDs formed were separated using high-speed centrifugation and

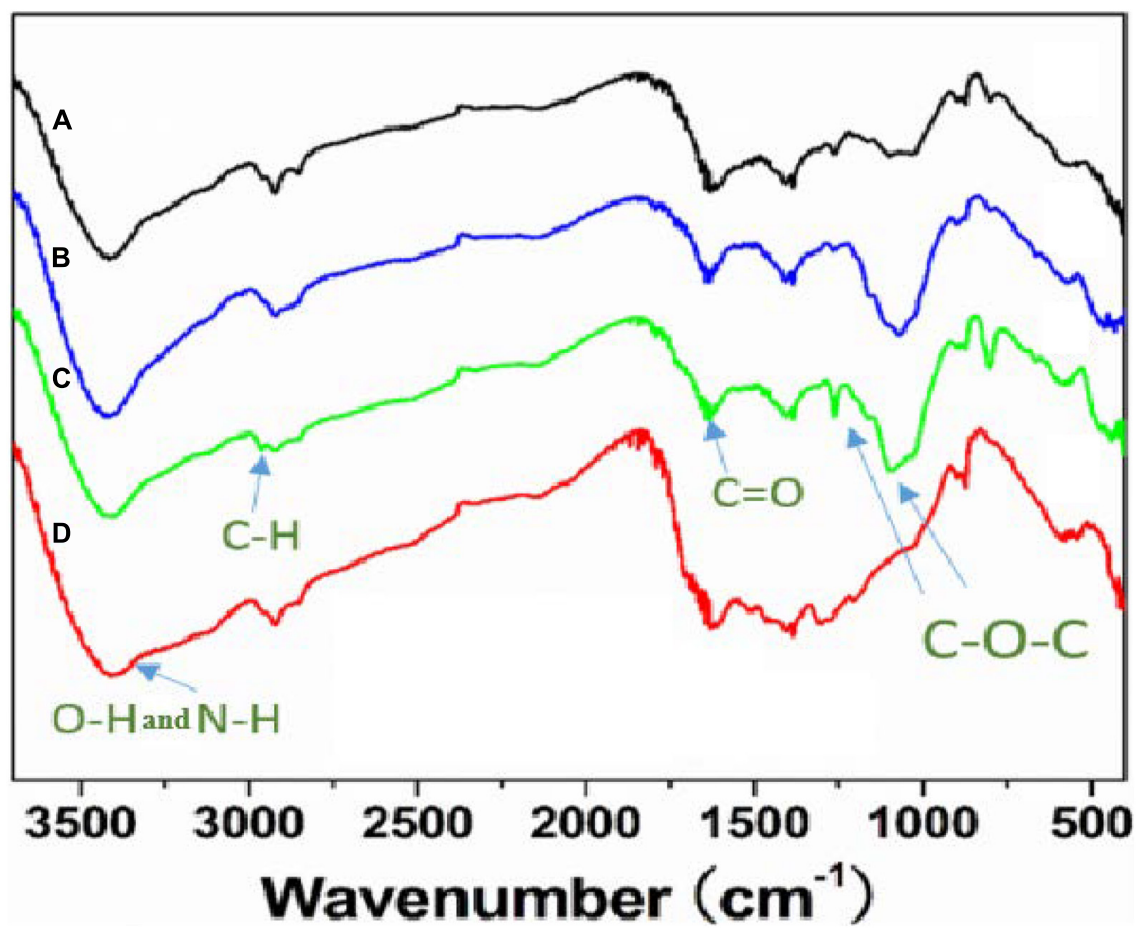

FIGURE 1 | FTIR spectra of different CDs samples prepared from differently pre-treated cellulose hydrogels: (A) CDs-4a; (B) CDs-3a; (C) CDs-2a; (D) Cellulose. 
A
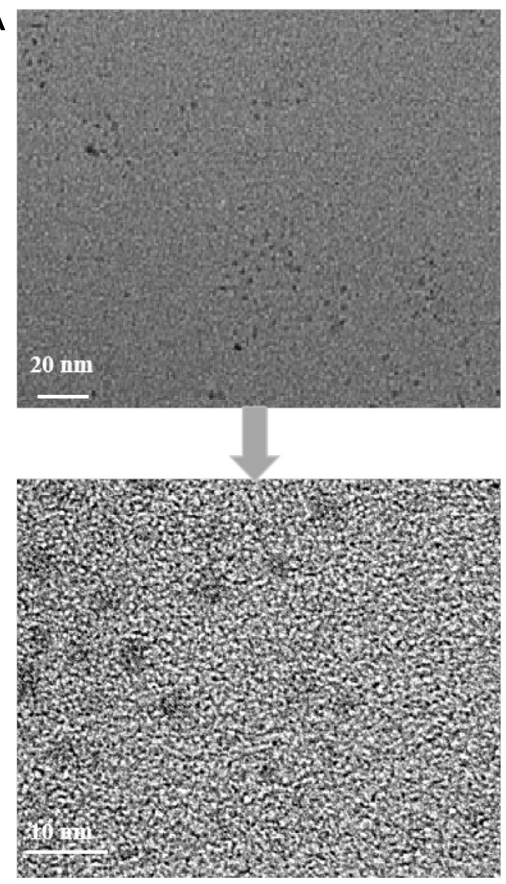

D

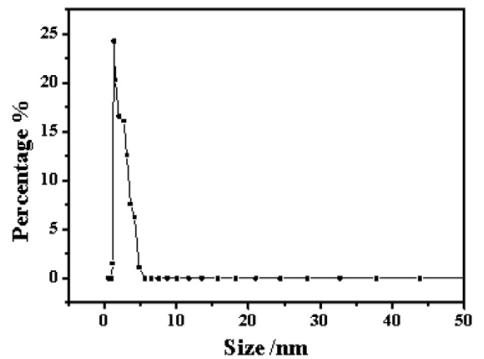

B
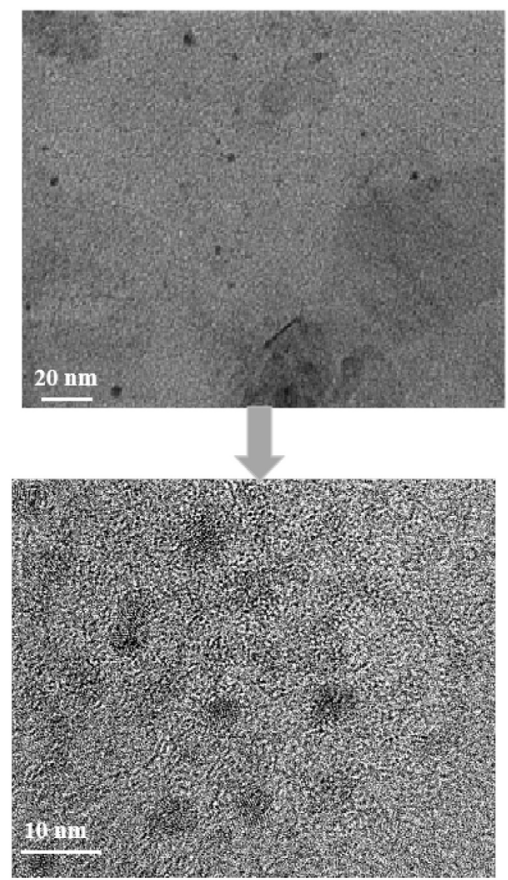

E

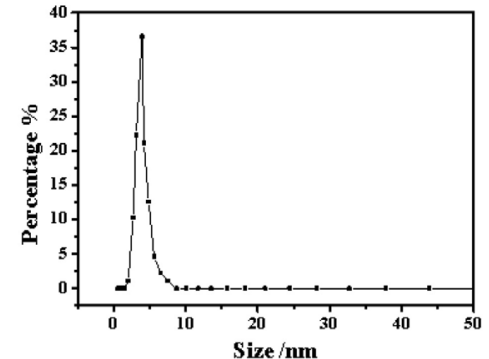

C

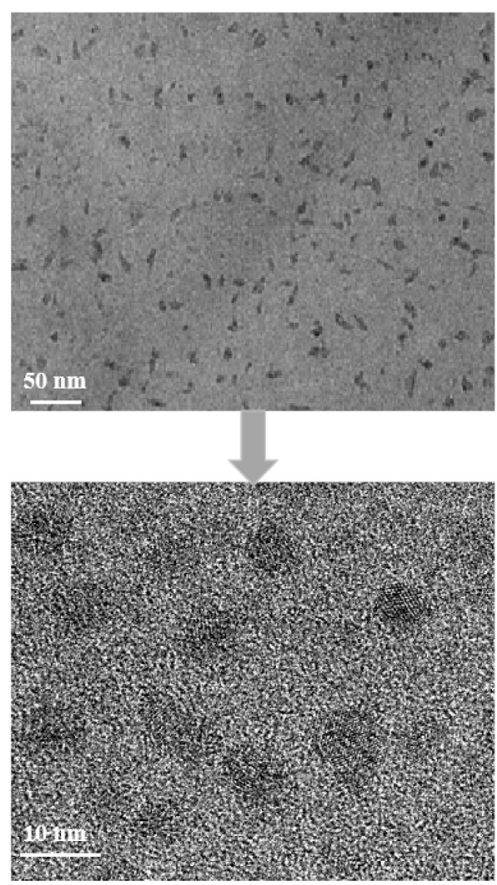

$\mathbf{F}$

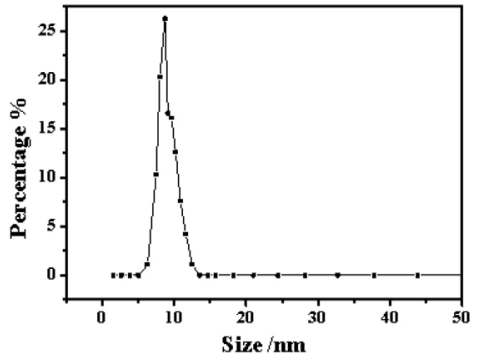

FIGURE 2 | The TEM images of CDs-4: (A) CDs-4a; (B) CDs-4b, and (C) CDs-4c. And the particle size of CDs-4: (D) CDs-4a; (E) CDs-4b, and (F) CDs-4c.

stored in ethyl alcohol. Next, the purified CDs were separated using dialysis bags with different molecular weight cut-off values (10 and $1.2 \mathrm{k})$; they were named CDs-a $(<1.2 \mathrm{k})$, CDs-b $(1.2-$ $10 \mathrm{k})$, CDs-c $(>10 \mathrm{k})$, respectively. In order to investigate the factors influencing hydrogel content, the pure cellulose hydrogel was pretreated with different methods before the hydrothermal reaction as described in the following. (1) The pure cellulose hydrogel was used directly without pretreatment. (2) The pure $4.5 \mathrm{~g}$ cellulose hydrogels were immersed in a $7 \mathrm{wt} \% \mathrm{NaOH}$ solution for $48 \mathrm{~h}$. (3) The pure $4.5 \mathrm{~g}$ cellulose hydrogels were immersed in a $12 \mathrm{wt} \%$ aqueous urea solution for $48 \mathrm{~h}$. (4) The pure $4.5 \mathrm{~g}$ cellulose hydrogels were immersed in a $(7 / 12 \%$, wt $\%)$ aqueous $\mathrm{NaOH}$-urea solution for $48 \mathrm{~h}$. The corresponding CDs were named as shown in Table $\mathbf{1}$.

\section{Characterization}

Fourier transform infrared (FTIR) spectra of the CDs were obtained using a Nicolet-Nexus 870 spectrophotometer. The $\mathrm{UV} /$ vis absorption of the CDs was measured using a CARY$100 \mathrm{UV} / \mathrm{Vis}$ spectrometer. The fluorescence spectra of the
TABLE 2 | The fluorescence quantum yield of different CDs samples.

\begin{tabular}{cccc}
\hline Sample & $\mathbf{a}$ & $\mathbf{b}$ & $\mathbf{c}$ \\
\hline CDs-1 & 0.008 & 0.002 & 0.005 \\
CDs-2 & 0.050 & 0.011 & 0.005 \\
CDs-3 & 0.179 & 0.034 & 0.013 \\
CDs-4 & 0.183 & 0.036 & 0.029
\end{tabular}

CDs were measured using a Hitachi F-4500. The morphology of the CDs was observed using a transmission electron microscope (TEM) at room temperature using a JEM-2010 (Rajendra et al., 2020). X-ray photoelectron spectroscopy (XPS) spectra were recorded with ESCALAB 250XI (Thermo Fisher Scientific, United States). The relative fluorescence quantum yield (QY) of the CDs was determined using methods previously reported in the literature (Shi et al., 2016; Khan et al., 2017; Liu et al., 2018). A quinine sulfate$\mathrm{H}_{2} \mathrm{SO}_{4}$ solution $(n=1.33$, QY $=0.54)$ was used as a reference solution. 


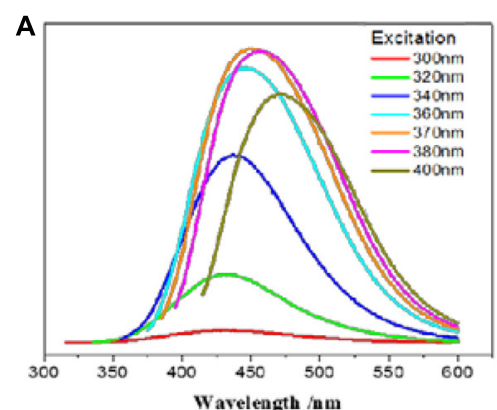

D

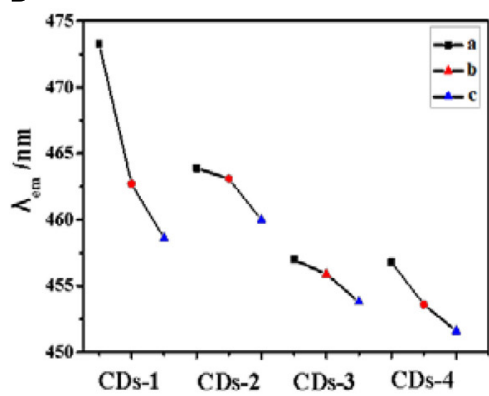

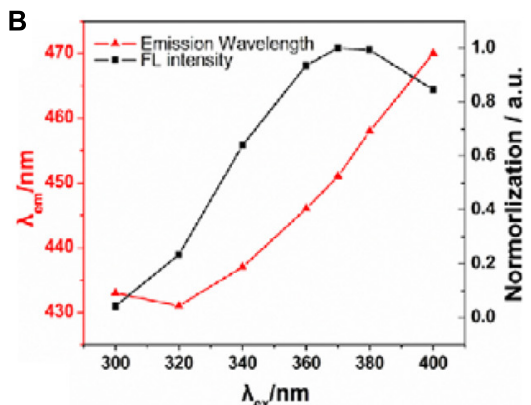

$E$

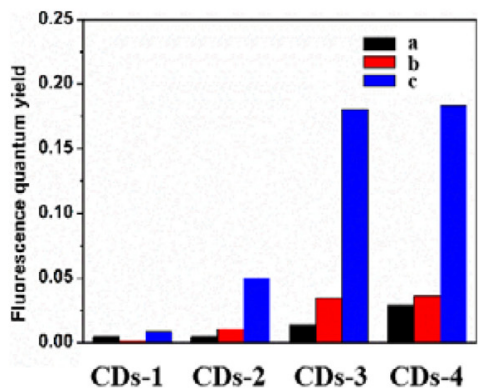

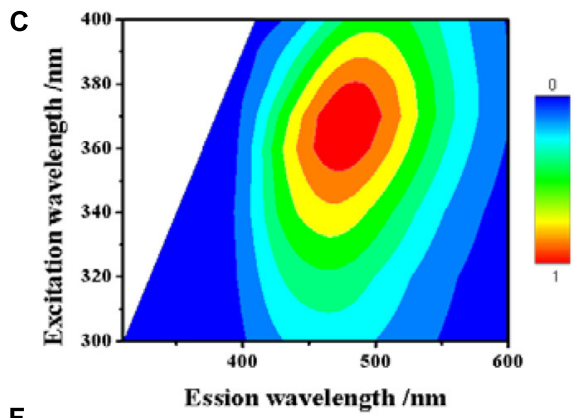

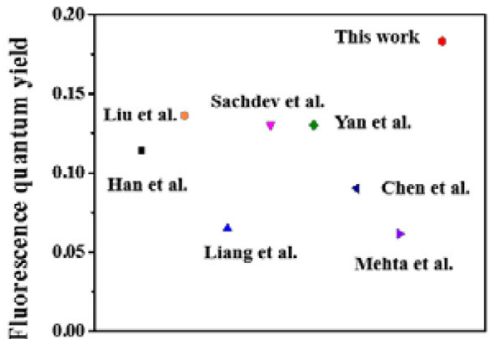

FIGURE 3 | The excitation-dependent PL behavior of the CDs-4a aqueous solution (A,B). (C) 2D excitation-emission contour map of CDs-4a at different excitation wavelengths. The emission wavelength of different CDs samples with the same excitation wavelength at $370 \mathrm{~nm}$ (D). The fluorescence quantum yield of different CDs samples (E). Comparison of fluorescence quantum yield of CDs-4a with reported CDs in the literatures (F).

The response of the CDs to metal stimuli was determined in a phosphate buffered saline (PBS) solution at $\mathrm{pH} 6.86$. A $10 \mu \mathrm{mol} / \mathrm{L}$ aliquot of a solution containing different metal ions $\mathrm{Hg}^{2+}, \mathrm{Ag}^{+}, \mathrm{Mn}^{2+}, \mathrm{Cr}^{3+}, \mathrm{Ca}^{2+}, \mathrm{Fe}^{3+}, \mathrm{Ni}^{2+}, \mathrm{Cu}^{2+}$, $\left.\mathrm{Co}^{2+}, \mathrm{Zn}^{2+}, \mathrm{Pb}^{2+}, \mathrm{Mg}^{2+}\right)$ was added into the CDs solution $(50 \mu \mathrm{g} / \mathrm{L})$. The fluorescence intensity at $450 \mathrm{~nm}$ was measured. Different metal ion solutions $(10 \mu \mathrm{mol} / \mathrm{L})$ were added into $3 \mathrm{~mL}$ of the CDs solution $(50 \mu \mathrm{g} / \mathrm{L})$, and the fluorescence intensity at emission wavelength of $450 \mathrm{~nm}$ was measured using fluorescence emission spectroscopy. $\mathrm{Hg}^{2+}$ solution with different concentration was added to the prepared CDs solution $(50 \mu \mathrm{g} / \mathrm{L})$, and the fluorescence intensity at emission wavelength of $450 \mathrm{~nm}$ was measured using fluorescence emission spectroscopy.

\section{In vitro Cytotoxicity Assay}

The influence of CDs-4a on the proliferation properties of an FL cell line was determined using a cell counting kit8 (CCK-8) assay. The FL cell line was seeded in 96-well culture plates with a density of $1 \times 10^{4}$ cells $/ \mathrm{cm}^{2}$ in a medium containing $10 \%$ fetal bovine serum and $1 \%$ penicillinstreptomycin. After $13 \mathrm{~h}$ of standard incubation, the cells adhered and spread over the bottom of the plate. Subsequently, the old cell culture medium was removed, and the cells were rinsed in the PBS solution. Next, $200 \mu \mathrm{L}$ of fresh media with varying concentrations of CDs was added for the continuous cell culture. At intervals of 24, 48, and $72 \mathrm{~h}$ later, the CCK-8 assay was performed in a dark environment to quantify the number of living cells. Fluorescence images of the trypsin digests cells labeled using CDs-4a with different particle sizes were obtained at an absorbance of $450 \mathrm{~nm}$ using the microplate reader (Gao et al., 2018; Malina et al., 2019; Ren et al., 2019).

\section{RESULTS AND DISCUSSION}

\section{Preparation and Characterization of CDs}

The FTIR spectra of the CDs are shown in Figure 1. The characteristic peak of the CDs at $3450 \mathrm{~cm}^{-1}$ relates to the stretching vibration of $-\mathrm{OH}$ and $-\mathrm{NH}$. The peak at $2910 \mathrm{~cm}^{-1}$ is the stretching vibration of $-\mathrm{CH}_{3}$. The characteristic peak at $1680 \mathrm{~cm}^{-1}$ corresponded to the stretching vibration of $\mathrm{C}=\mathrm{O}$, which resulted from $\mathrm{C}-\mathrm{OH}$ oxidation during the hydrothermal reaction. This reaction is regarded as a luminescence emission source that can be used for fluorescence detection. It is worth noting that, compared with cellulose there was an obvious change of the characteristic peaks at $1230 \mathrm{~cm}^{-1}$ and $1100 \mathrm{~cm}^{-1}$ corresponding to the stretching vibrations of $\mathrm{C}-\mathrm{O}-\mathrm{C}$, in the other types of CDs. This can be attributed to the ring-opening reaction of cellulose and its subsequent oxidation in the presence of $\mathrm{NaOH}$ or urea. The morphology of the $\mathrm{NaOH} /$ urea/cellulose CDs-4 was studied using TEM. As shown in Figures 2A-C, the CDs-4 particles were almost spherical in structure and exhibited no agglomeration or decomposition. In order to investigate the effect of particle size, the CDs- 4 particles were separated into CDs-4a, CDs- $4 \mathrm{~b}$, and CDs-4c using a dialysis bag with different molecular weight cut-off values; the higher the molecular weight, the bigger the particle size. Figure 2D shows the distribution of diameters for CDs-4a, CDs-4b, and CDs-4c were 2.11, 3.94, and $8.72 \mathrm{~nm}$, respectively (Table $\mathbf{1}$ ). 

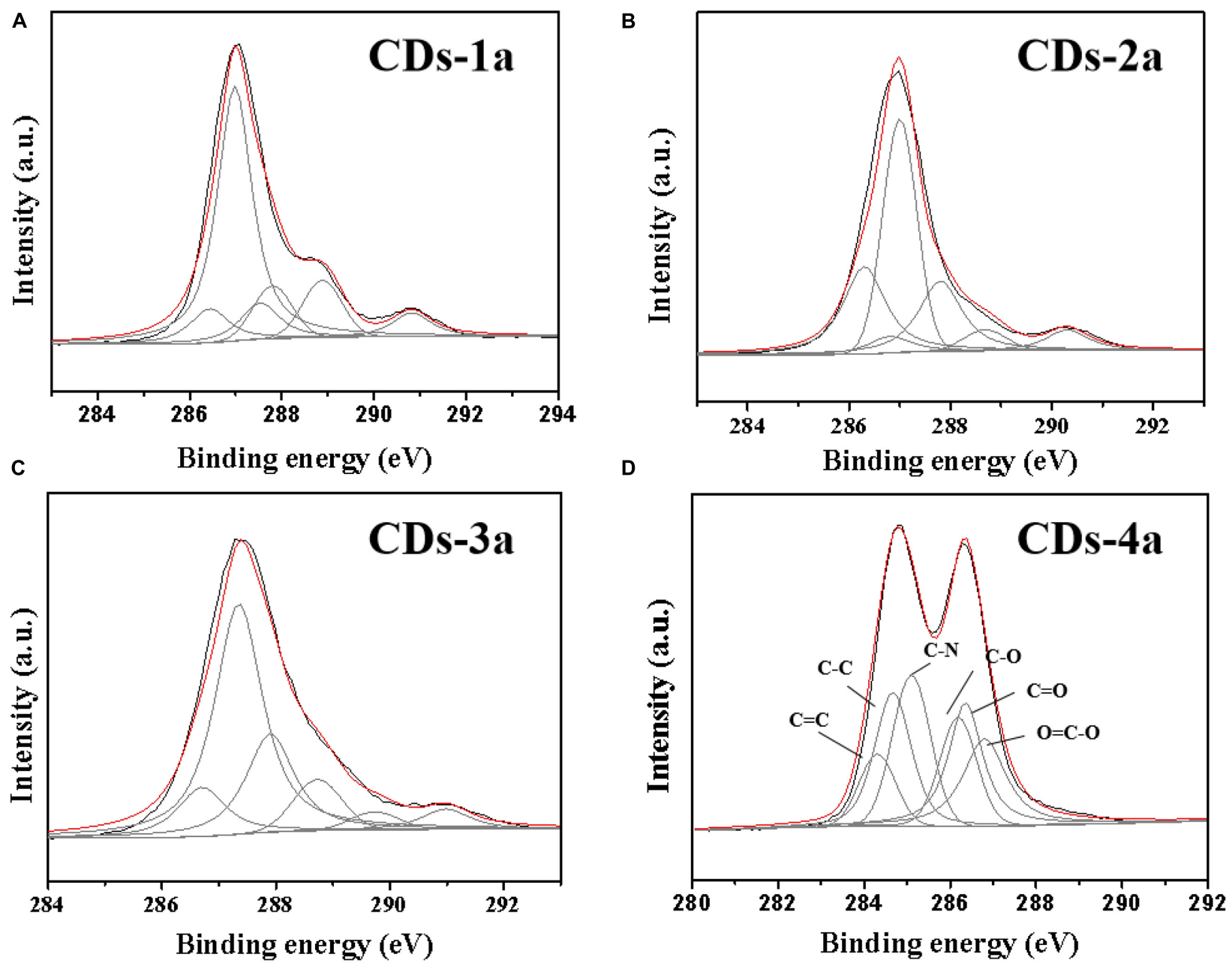

FIGURE 4 | The XPS spectra of CDs: (A) CDs-1a; (B) CDs-2a; (C) CDs-3a, and (D) CDs-4a.

TABLE 3 | The elements content and functional groups of different CDs samples.

\begin{tabular}{lcrrrrr}
\hline Sample & $\mathbf{C}$ at $\%$ & $\mathbf{N}$ at $\%$ & $\mathbf{0}$ at\% & $\mathbf{C = C} \%$ & $\mathbf{C = 0} \%$ & $\mathbf{C - N} \%$ \\
\hline CDs-1a & 82.74 & 1.06 & 16.19 & 8.69 & 15.92 & 6.76 \\
CDs-2a & 86.07 & 1.59 & 12.35 & 9.13 & 16.46 & 3.05 \\
CDs-3a & 74.31 & 6.97 & 18.72 & 12.29 & 20.99 & 17.63 \\
CDs-4a & 74.15 & 7.77 & 18.07 & 14.62 & 21.05 & 19.18 \\
\hline
\end{tabular}

\section{Fluorescence Properties of CDs}

In order to investigate the fluorescence properties of CDs-4a, the excitation wavelength of CDs-4a was measured at wavelengths between 300 and $400 \mathrm{~nm}$. As shown in Figures 3A-C, under the excitation wavelength of $370 \mathrm{~nm}$, the fluorescence spectra of the CDs- 4 exhibited a strong, single peak at $450 \mathrm{~nm}$. Thus, an excitation wavelength of $370 \mathrm{~nm}$ was used for the following investigations. In addition, at the same excitation wavelength of $370 \mathrm{~nm}$, it was found that the emission wavelength decreased as the particle size increased (Figure 3D). This results from the fact that the CDs particle size significantly affects the number of conjugated structures (Tao et al., 2017; Barman and Patra, 2018; Yan et al., 2019). Furthermore, the addition of $\mathrm{NaOH}$ or urea also affects the emission wavelength, leading to a blue shift. The maximum emission wavelengths of CDs-4a, CDs- $4 b$, and CDs- $4 c$ were 450, 455, and $460 \mathrm{~nm}$, respectively.

The relative fluorescence QY is an important factor in determining the fluorescence performance of fluorescent materials (Angshuman et al., 2016). Thus, the fluorescence QY of the different types of CDs was measured to evaluate the fluorescence properties. As shown in Figure 3E (Table 2), among all the types of CDs, CDs-1 exhibited the lowest QY. The introduction of $\mathrm{NaOH}$ or urea resulted in an obvious enhancement of the QY. Among all the samples, the CDs-4 exhibited the highest QY and the best fluorescence performance. Compared with most previously reported CDs, the QY of CDs-4a exhibits a higher performance of 0.183 (Figure 3F; Mehta et al., 2014; Sachdev and Gopinath, 2015; Chen et al., 2016; Liang et al., 2016; Yan et al., 2016; Liu et al., 2017; Han et al., 2018). This was a result of the effective promotion of the ring-opening and subsequent oxidation reaction of cellulose following the 

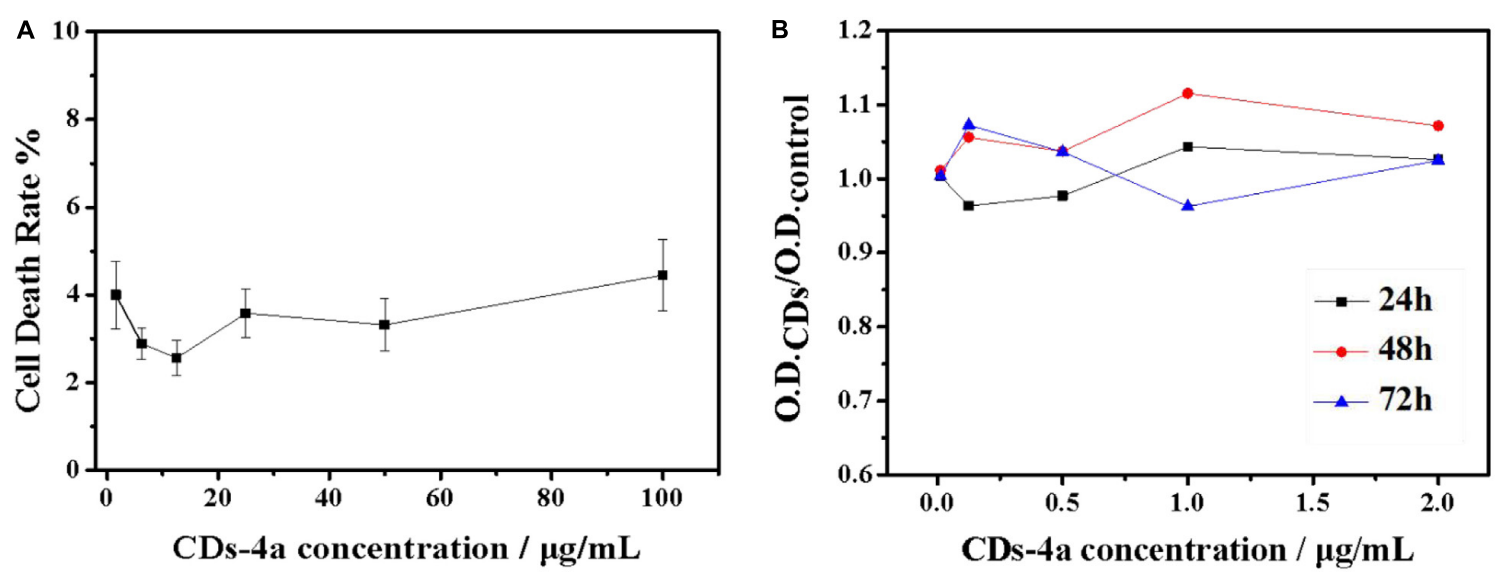

C
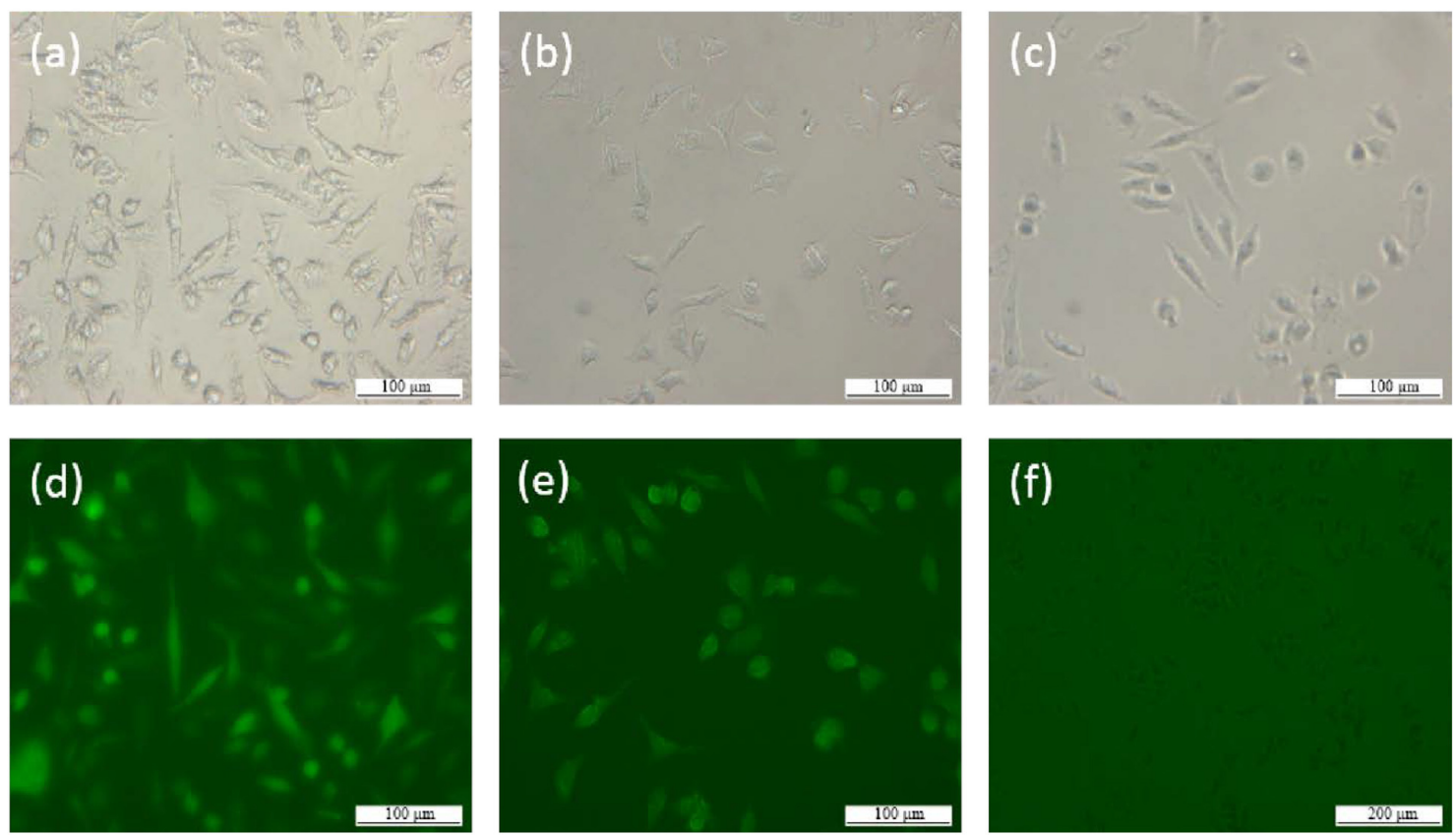

FIGURE 5 | (A) Curve of acute toxicity test of CDs-4a with different concentration. (B) Cytostasis curve of CDs-4a with different concentration in 24 , 48 , and $72 \mathrm{~h}$. (C) The FL cells images of (a) CDs-4a, (b) CDs-4b, (c) CDs-4c under visible light and (d) CDs-4a, (e) CDs-4b, (f) CDs-4c under the UV excitation.

addition of $\mathrm{NaOH}$ or urea, which also provided increased doping of elements.

An XPS analysis of the CDs was performed (Figure 4 and Table 3). It was found that, CDs-3a and CDs-4a contained a higher nitrogen content than that of CDs-1a and CDs-2a. This demonstrated that, the addition of urea increased the amount of nitrogen functional groups in the CDs during the hydrothermal reaction. Furthermore, the C1S spectrum indicated that the amount of $\mathrm{C}=\mathrm{C} / \mathrm{C}=\mathrm{O}$ and $\mathrm{C}-\mathrm{N}$ functional groups in CDs-3a and CDs-4a was substantially higher than that of CDs-1a and CDs-2a, and as such an effective auxochrome was produced that enhanced the relative fluorescence emission efficiency. Hence, in comparison with the other samples, the CDs-3a and CDs-4a exhibited the best relative fluorescence emission efficiency.
In addition, for CDs pretreated using the same method, the particle size significantly influenced the QY. With increasing particle size, the QY obviously decreased. For example, the QY of CDs-4a was 0.18, which was much higher than that of CDs$4 \mathrm{~b}$ and CDs-4c. This may be attributed to the smaller particle size and corresponding high number of luminous groups on the surface. Due to their excellent relative fluorescence emission efficiency, the CDs-4a were regarded as the ideal candidate for use in the remainder of this study.

\section{Biocompatibility of CDs-4}

In terms of future applications, assessment of the potential cytotoxicity of the biocompatible CDs is extremely important. As such, the biocompatibility of the CDs-4a was evaluated using FL cells. As shown in Figure 5A, after $12 \mathrm{~h}$ incubation, the cell death 

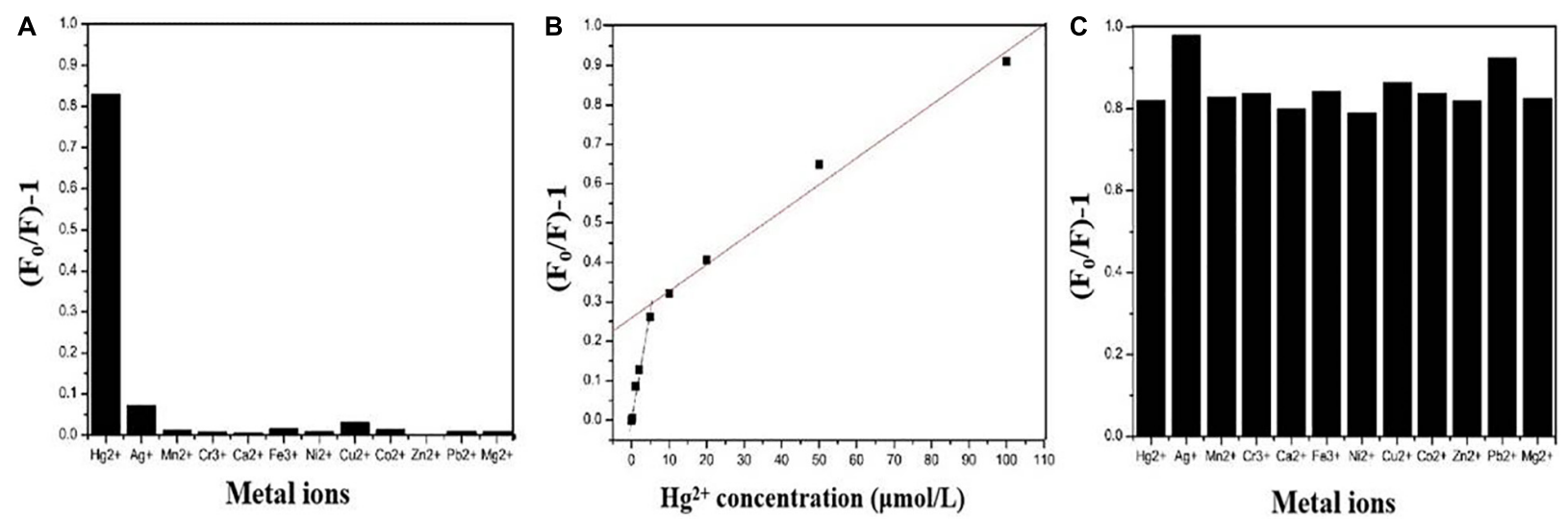

FIGURE 6 | Fluorescent response of CDs-4a in the presence of $10 \mu \mathrm{M}$ of different metal ions (A). Plots of the values of ( $\left.\mathrm{F}_{0} / \mathrm{F}\right)-1$ versus the concentration of $\mathrm{Hg} \mathrm{g}^{2+}$ (B). Fluorescence response of CDs-4a in the presence of $10 \mu \mathrm{M} \mathrm{Hg}^{2+}$ and $10 \mu \mathrm{M}$ another kind of metal ions (C).

TABLE 4 | Detection limit and linear range of $\mathrm{Hg}^{2+}$ detectors.

\begin{tabular}{lccl}
\hline Detection probes & $\begin{array}{c}\text { Linear range } \\
(\boldsymbol{\mu} \mathbf{~ M )}\end{array}$ & $\begin{array}{c}\text { Detection } \\
\text { limit }(\boldsymbol{\mu} \mathbf{~ M )}\end{array}$ & References \\
\hline Hydrogel CDs & $0.2-10,10-100$ & 0.2 & This work \\
Eu ${ }^{3+}$-CDs & $5-250$ & 2.2 & Desai et al., 2018 \\
N,S-CDs & $1-75$ & 0.5 & Xu et al., 2018 \\
N-CQDs & $0-25$ & 0.23 & Zhang H. et al., 2020 \\
TFIC MNPs & $4-16$ & 5.04 & Wang et al., 2013 \\
Polymer sensor & $1-30$ & 0.728 & Li et al., 2012 \\
NCDs & $0.9-10$ & 0.15 & Zhang C. et al., 2020
\end{tabular}

rate remained below 5\%, even at high CDs-4a concentrations of up to $100 \mu \mathrm{g} / \mathrm{mL}$. Cytostatic curves of the CDs-4a were obtained at different concentrations. Figure 5B shows the cell viability following treatment with different concentrations of CDs for 24, 48, and $72 \mathrm{~h}$. The exert concentration of CDs at different concentrations did not result in a significant decrease in cell viability after $72 \mathrm{~h}$, which suggests good biocompatibility. This result is similar with the results of other biocompatible CDs from natural polymer biomaterials (Sharma et al., 2017; Zhou et al., 2017; Zhang et al., 2018; Meng et al., 2019; Zulfajiri et al., 2020).

Figure 5C shows fluorescence images of trypsin digests cells labeled using different sized CDs-4. The brightest regions are the CDs-4a, indicating they can be clearly distinguished; therefore, the CDs-4a displayed the best fluorescence performance. As well as a high QY value, the CDs-4a have a small particle size meaning they are easily taken up by cells. These cytotoxicity results imply that the CDs-4a prepared from hydrogels have potential for use in the labeling of living cells.

\section{Specific Detection of CDs-4a for $\mathrm{Hg}^{2+}$}

Figure 6A shows the fluorescence response performance of CDs4a to different heavy metal ions. Compared with other metal ions, CDs-4a exhibited a specific response to $\mathrm{Hg}^{2+}$ ions. The addition of $\mathrm{Hg}^{2+}$ ions significantly quenched the fluorescence of CDs-4a, indicating promise for application in the selective detection of heavy metal ions. It could be attributed to the strong interactions between $\mathrm{Hg}^{2+}$ and functional groups of $\mathrm{C}=\mathrm{C} / \mathrm{C}=\mathrm{O}$ and $\mathrm{C}-\mathrm{N}$ of CDs-4a, which could effectively reduce the relative fluorescence strength. In order to evaluate the ability of the CDs-4a to detect $\mathrm{Hg}^{2+}$, the fluorescence quenching intensity of the CDs-4a was measured at various $\mathrm{Hg}^{2+}$ ion concentrations and calculated using the Stern-Volmer equation:

$$
\frac{F_{0}}{F}-1=\mathrm{K}[Q]
$$

Where $F_{0}$ and $F$ represent the fluorescence intensity of the fluorophore in the absence and presence of metal ions, respectively. $\mathrm{K}$ is the Stern-Volmer constant, and [Q] is the metal ion concentration. As shown in Figure $\mathbf{6 B}$, the fluorescence quenching intensity obviously increased when the metal ion concentration was increased from 0.2 to $100 \mu \mathrm{mol} / \mathrm{L}$. A two-stage, concentration-dependent fluorescence response was observed. Both stages exhibited a good linear relationship between $\left(F_{0} / F-1\right)$ and concentration, ranging from 0.2 to $10 \mu \mathrm{mol} / \mathrm{L}\left(R^{2}=0.9948, K=5.88 \times 10^{4}\right)$ and from 10 to $100 \mu \mathrm{mol} / \mathrm{L}\left(R^{2}=0.9911, K=6.66 \times 10^{3}\right)$. The Stern-Volmer constant varies above and below a concentration of $10 \mu \mathrm{mol} / \mathrm{L}$. In the low concentration stage, the slope is steep, and in the high concentration stage, the slope is less steep, which means that CDs-4a is more sensitive under lower concentration conditions. When the metal ion concentration was $0.2 \mu \mathrm{mol} / \mathrm{L}$, the CDs4a retained their $\mathrm{Hg}^{2+}$ detection ability and the fluorescence quenching intensity was maintain at approximately 0.1 , which suggests a good sensitivity toward $\mathrm{Hg}^{2+}$ ions. Compared with most reports of $\mathrm{Hg}^{2+}$ ion detection, the CDs-4a displayed an excellent ability to detect $\mathrm{Hg}^{2+}$ ions (Table 4; Li et al., 2012; Wang et al., 2013; Desai et al., 2018; Xu et al., 2018; Zhang C. et al., 2020; Zhang H. et al., 2020). Based on the good linear relationship and low detection limit, the CDs-4a are able to specifically detect $\mathrm{Hg}^{2+}$ ions as well as quantify the concentration of $\mathrm{Hg}^{2+}$ ions. 
During practical applications, interference from other metal ions that co-exist with $\mathrm{Hg}^{2+}$ ions in solution may affect the detection. To study the effect of these interfering ions, further experiments were performed. The ability of CDs-4a to detect $\mathrm{Hg}^{2+}$ ions in the presence of other, interfering metal ions was determined. Figure $\mathbf{6 C}$ shows the fluorescence quenching intensity measured in a solution of $\mathrm{Hg}^{2+}$ mixed with other ions, it was observed that the fluorescence quenching intensity of almost all the other ions was similar to that of the pure $\mathrm{Hg}^{2+}$ solution, only $\mathrm{Ag}^{+}$and $\mathrm{Pb}^{2+}$ slightly increased the fluorescence quenching intensity. These results indicate the CDs-4a have the capacity to resist interference from other ions during the detection of $\mathrm{Hg}^{2+}$ ions, which is significant in practical applications.

\section{CONCLUSION}

In this work, a series of novel, biocompatible CDs were prepared from the natural polymer, cellulose hydrogel. Using an effective pretreatment method, the fluorescence performance was enhanced. Using dialysis bags with different molecular weight cut-off values, the CDs were separated into samples with different particle size. With the decrease of the particle size, the fluorescence QY of CDs increased. The CDs-4a exhibited good fluorescence during living cell labeling due to their small particle size and the presence of functional groups on the particle surface. More importantly, the CDs-4a exhibited specific detection of the heavy metal ion $\mathrm{Hg}^{2+}$ with high sensitivity. The LOD was as

\section{REFERENCES}

Ali, H., and Khan, E. (2018). Bioaccumulation of non-essential hazardous heavy metals and metalloids in freshwater fish. Risk to human health. Environ. Chem. Lett. 16, 903-917. doi: 10.1007/s10311-018-0734-7

Angshuman, R. C., Tanya, S., Sudip, K. G., and Sumanta, K. S. (2016). Carbon dots embedded magnetic Nanoparticles@Chitosan @Metal organic framework as a nanoprobe for $\mathrm{pH}$ sensitive targeted anticancer drug delivery. ACS Appl. Mater. Interfaces 8, 16573-16583. doi: 10.1021/acsami.6b03988

Ansi, V. A., and Renuka, N. K. (2019). Exfoliated graphitic carbon dots: application in heavy metal ion sensing. J. Lumin. 205, 467-474. doi: 10.1016/j.jlumin.2018. 09.061

Bansod, B., Kumar, T., Thakur, R., Rana, S., and Singh, I. (2017). A review on various electrochemical techniques for heavy metal ions detection with different sensing platforms. Biosens. Bioelectron. 94, 443-455. doi: 10.1016/j.bios.2017.03. 031

Barman, M. K., and Patra, A. (2018). Current status and prospects on chemical structure driven photoluminescence behaviour of carbon dots. J. Photoch. Photobio. C. 37, 1-22. doi: 10.1016/j.jphotochemrev.2018. 08.001

Bolisetty, S., Peydayesh, M., and Mezzenga, R. (2019). Sustainable technologies for water purification from heavy metals: review and analysis. Chem. Soc. Rev. 48, 463-487. doi: 10.1039/c8cs00493e

Cai, L. M., Wang, Q. S., Luo, J., Chen, L. G., Zhu, R. L., Wang, S., et al. (2019). Heavy metal contamination and health risk assessment for children near a large Cu-smelter in central China. Sci. Total Environ. 650, 725-733. doi: 10.1016/j. scitotenv.2018.09.081

Chen, Y., Wu, Y., Weng, B., Wang, B., and Li, C. (2016). Facile synthesis of nitrogen and sulfur co-doped carbon dots and application for Fe (III) ions detection and cell imaging. Sens. Actuators B Chem. 223, 689-696. doi: 10.1016/j.snb.2015.09. 081

Desai, M. L., Jha, S., Basu, H., Singhal, R. K., Sharma, P. K., and Kailasa, S. K. (2018). Microwave-assisted synthesis of water-soluble Eu3+ hybrid carbon dots with low as $0.2 \mu \mathrm{M}$ and a two stage linear detection $(0.2-10$ and 10-100 $\mu \mathrm{M})$ was observed. The CDs-4a also maintained an excellent detection ability, even in complex solutions containing interference metal ions, such as $\mathrm{Fe}^{3+}, \mathrm{Zn}^{2+}, \mathrm{Mg}^{2+}$, and $\mathrm{Ni}^{2+}$. We believe this work will provide novel insights into the development of high-performance multifunctional CDs based on a low-cost and natural polymer, cellulose hydrogel.

\section{DATA AVAILABILITY STATEMENT}

The original contributions presented in the study are included in the article/supplementary material, further inquiries can be directed to the corresponding authors.

\section{AUTHOR CONTRIBUTIONS}

MX and XW proposed the idea. HH and HG did the experiments. $\mathrm{ZH}$ helped the property evaluation of CDs. ZR helped the vitro cytotoxicity assay of CDs. All authors contributed to the article and approved the submitted version.

\section{FUNDING}

This work was supported by the National Key Research and Development Program of China (No. 2018YFC1602800).

enhanced fluorescence for the sensing of $\mathrm{Hg} 2+$ ions and imaging of fungal cells. New J. Chem. 42, 6125-6133. doi: 10.1039/c7nj04835a

Gao, W., Song, H., Wang, X., Liu, X., Pang, X., Zhou, Y., et al. (2018). Carbon dots with red emission for sensing of $\mathrm{Pt}(2+), \mathrm{Au}(3+)$, and $\mathrm{Pd}(2+)$ and their bioapplications in vitro and in vivo. ACS Appl. Mater. Interfaces 10, 1147-1154. doi: 10.1021/acsami.7b16991

Han, M., Zhu, S., Lu, S., Song, Y., Feng, T., Tao, S., et al. (2018). Recent progress on the photocatalysis of carbon dots: classification, mechanism and applications. Nano Today 19, 201-218. doi: 10.1016/j.nantod.2018.02.008

Huang, H., Wang, X., Ge, H., and Xu, M. (2016). Multifunctional magnetic cellulose surface-imprinted microspheres for highly selective adsorption of artesunate. ACS Sustainable Chem. Eng. 4, 3334-3343. doi: 10.1021/ acssuschemeng.6b00386

Kahlon, S. K., Sharma, G., Julka, J. M., Kumar, A., Sharma, S., and Stadler, F. J. (2018). Impact of heavy metals and nanoparticles on aquatic biota. Environ. Chem. Lett. 16, 919-946. doi: 10.1007/s10311-018-0737-4

Khan, W. U., Wang, D., Zhang, W., Tang, Z., Ma, X., Ding, X., et al. (2017). High quantum yield green-emitting carbon dots for Fe(capital I, Ukrainiancapital I, Ukrainiancapital I, Ukrainian) detection, biocompatible fluorescent ink and cellular imaging. Sci. Rep. 7:14866. doi: 10.1038/s41598-017-15054-9

Kumar, A., Kumar, A. M., Cabral-Pinto, M. S., Chaturvedi, A. K., Shabnam, A. A., Subrahmanyam, G., et al. (2020). Lead toxicity: health hazards, influence on food chain, and sustainable remediation approaches. Int. J. Environ. Res. Public Health. 17:2179. doi: 10.3390/ijerph17072179

Li, J. F., Wu, Y. Z., Song, F. Y., Wei, G., Cheng, Y. X., and Zhu, C. J. (2012). A highly selective and sensitive polymer-based OFF-ON fluorescent sensor for $\mathrm{Hg} 2+$ detection incorporating salen and perylenyl moieties. J. Mater. Chem. 22, 478-482. doi: 10.1039/C1JM14037J

Li, Z., Chen, J., Guo, H., Fan, X., Wen, Z., Yeh, M. H., et al. (2016). Triboelectrification-enabled self-powered detection and removal of heavy metal ions in wastewater. Adv. Mater. 28, 2983-2991. doi: 10.1002/adma.201504356

Liang, Z., Kang, M., Payne, G. F., Wang, X., and Sun, R. (2016). Probing energy and electron transfer mechanisms in fluorescence quenching of biomass carbon 
quantum dots. ACS Appl. Mater. Interfaces 8, 17478-17488. doi: 10.1021/ acsami.6b04826

Liu, H., Li, Z., Sun, Y., Geng, X., Hu, Y., Meng, H., et al. (2018). Synthesis of luminescent carbon dots with ultrahigh quantum yield and inherent folate receptor-positive cancer cell targetability. Sci. Rep. 8:1086. doi: 10.1038/s41598018-19373

Liu, M. L., Chen, B. B., Li, C. M., and Huang, C. Z. (2019). Carbon dots: synthesis, formation mechanism, fluorescence origin and sensing applications. Green Chem. 21, 449-471. doi: 10.1039/c8gc02736f

Liu, W., Diao, H., Chang, H., Wang, H., Li, T., and Wei, W. (2017). Green synthesis of carbon dots from rose-heart radish and application for Fe3+ detection and cell imaging. Sens. Actuators B Chem. 241, 190-198. doi: 10.1016/j.snb.2016.10. 068

Lu, Y., Liang, X., Niyungeko, C., Zhou, J., Xu, J., and Tian, G. (2018). A review of the identification and detection of heavy metal ions in the environment by voltammetry. Talanta 178, 324-338. doi: 10.1016/j.talanta.2017.08.033

Malik, L. A., Bashir, A., Qureashi, A., and Pandith, A. H. (2019). Detection and removal of heavy metal ions: a review. Environ. Chem. Lett. 17, 1495-1521. doi: 10.1007/s10311-019-00891-z

Malina, T., Poláková, K., Skopalík, J., Milotová, V., Holá, K., Havrdová, M., et al. (2019). Carbon dots for in vivo fluorescence imaging of adipose tissue-derived mesenchymal stromal cells. Carbon 152, 434-443. doi: 10.1016/j.carbon.2019. 05.061

Mehta, V. N., Jha, S., Singhal, R. K., and Kailasa, S. K. (2014). Preparation of multicolor emitting carbon dots for HeLa cell imaging. New J. Chem. 38, 6152-6160. doi: 10.1039/C4NJ00840E

Meng, W., Bai, X., Wang, B., Liu, Z., Lu, S., and Yang, B. (2019). Biomass-derived carbon dots and their applications. Energy Environ. Mater. 2, 172-192. doi: 10.1002/eem 2.12038

Oliveira, C. S., Segatto, A. L. A., Nogara, P. A., Piccoli, B. C., Loreto, E. L. S., Aschner, M., et al. (2020). Transcriptomic and proteomic tools in the study of hg toxicity: what is missing? Front. Genet. 11:425. doi: 10.3389/fgene.2020.00425

Pang, Y., Gao, H., Wu, S., and Li, X. (2017). Facile synthesis the nitrogen and sulfur co-doped carbon dots for selective fluorescence detection of heavy metal ions. Mater. Lett. 193, 236-239. doi: 10.1016/j.matlet.2017.01.149

Patel, K. D., Singh, R. K., and Kim, H. W. (2019). Carbon-based nanomaterials as an emerging platform for theranostics. Mater. Horiz. 6, 434-469. doi: 10.1039/ C8MH00966

Qi, Y., Ma, J., Chen, X., Xiu, F. R., Chen, Y., and Lu, Y. (2020). Practical aptamerbased assay of heavy metal mercury ion in contaminated environmental samples: convenience and sensitivity. Anal. Bioanal. Chem. 412, 439-448. doi: 10.1007/s00216-019-02253-8

Rajendra, K. S., Amal, G. K., Kapil, D. P., Nandin, M., Na-Hyun, L., Jonathan, C. K., et al. (2020). Label-free fluorescent mesoporous bioglass for drug delivery, optical triple-mode imaging, and photothermal/photodynamic synergistic cancer therapy. ACS Appl. Bio. Mater. 3, 2218-2229. doi: 10.1021/acsabm. $0 \mathrm{c} 00050$

Ren, Z., Huang, H., Zhang, J., Qi, H., Xu, M., and Wang, X. (2019). Cellulose hydrogel is a novel carbon-source and doping-material-carrier to prepare fluorescent carbon dots for intracellular bioimaging. SN Appl. Sci. 2:17. doi: 10.1007/s42452-019-1794-4

Rossini-Oliva, S., Abreu, M. M., Santos, E. S., and Leidi, E. O. (2020). Soilplant system and potential human health risk of Chinese cabbage and oregano growing in soils from $\mathrm{Mn}$ and $\mathrm{Fe}$ abandoned mines: microcosm assay. Environ. Geochem. Health. 42, 4073-4086. doi: 10.1007/s10653-020-00514-5

Sachdev, A., and Gopinath, P. (2015). Green synthesis of multifunctional carbon dots from coriander leaves and their potential application as antioxidants, sensors and bioimaging agents. Analyst 140, 4260-4269. doi: 10.1039/ C5AN00454C

Sarma, G. K., Sen Gupta, S., and Bhattacharyya, K. G. (2019). Nanomaterials as versatile adsorbents for heavy metal ions in water: a review. Environ. Sci. Pollut. Res. Int. 26, 6245-6278. doi: 10.1007/s11356-018-04093-y

Sharma, V., Tiwari, P., and Mobin, S. M. (2017). Sustainable carbon-dots: recent advances in green carbon dots for sensing and bioimaging. J. Mater. Chem B. 5 , 8904-8924. doi: 10.1039/c7tb02484c

Shi, L., Yang, J. H., Zeng, H. B., Chen, Y. M., Yang, S. C., Wu, C., et al. (2016). Carbon dots with high fluorescence quantum yield: the fluorescence originates from organic fluorophores. Nanoscale 8, 14374-14378. doi: 10.1039/ c6nr00451b
Tao, S., Song, Y., Zhu, S., Shao, J., and Yang, B. (2017). A new type of polymer carbon dots with high quantum yield: from synthesis to investigation on fluorescence mechanism. Polymer 116, 472-478. doi: 10.1016/j.polymer.2017. 02.039

Wang, B., Tan, H., Zhang, T., Duan, W., and Zhu, Y. (2019). Hydrothermal synthesis of $\mathrm{N}$-doped carbon dots from an ethanolamine-ionic liquid gel to construct label-free multifunctional fluorescent probes for $\mathrm{Hg} 2+, \mathrm{Cu} 2+$ and S2O32-. Analyst 144, 3013-3022. doi: 10.1039/c9an00116f

Wang, C., Wang, C., Xu, P., Li, A., Chen, Y., and Zhuo, K. (2015). Synthesis of cellulose-derived carbon dots using acidic ionic liquid as a catalyst and its application for detection of $\mathrm{Hg} 2+$. J. Mater. Sci. 51, 861-867. doi: 10.1007/ s10853-015-9410-5

Wang, W., Zhang, Y., Yang, Q. B., Sun, M. D., Fei, X. L., Song, Y., et al. (2013). Fluorescent and colorimetric magnetic microspheres as nanosensors for $\mathrm{Hg} 2+$ in aqueous solution prepared by a sol-gel grafting reaction and host-guest interaction. Nanoscale 5, 4958-4965. doi: 10.1039/C3NR0 0580A

Wu, Y., Pang, H., Liu, Y., Wang, X., Yu, S., Fu, D., et al. (2019). Environmental remediation of heavy metal ions by novel-nanomaterials: a review. Environ. Pollut. 246, 608-620. doi: 10.1016/j.envpol.2018.12.076

Wu, Z. L., Liu, Z. X., and Yuan, Y. H. (2017). Carbon dots: materials, synthesis, properties and approaches to long-wavelength and multicolor emission. J. Mater. Chem. B. 5, 3794-3809. doi: 10.1039/c7tb00363c

Xu, Y., Li, H., Wang, B., Liu, H., Zhao, L., Zhou, T. Y., et al. (2018). Microwaveassisted synthesis of carbon dots for "turn-on" fluorometric determination of $\mathrm{Hg}$ (II) via aggregation-induced emission. Mikrochim. Acta 185:252. doi: 10. 1007/s00604-018-2781-y

Yan, F., Sun, Z., Zhang, H., Sun, X., Jiang, Y., and Bai, Z. (2019). The fluorescence mechanism of carbon dots, and methods for tuning their emission color: a review. Mikrochim. Acta. 186:583. doi: 10.1007/s00604-019-3688-y

Yan, Z., Zhang, Z., and Chen, J. (2016). Biomass-based carbon dots: synthesis and application in imatinib determination. Sens. Actuators B Chem. 225, 469-473. doi: 10.1016/j.snb.2015.10.107

Yarur, F., Macairan, J. R., and Naccache, R. (2019). Ratiometric detection of heavy metal ions using fluorescent carbon dots. Environ. Sci. 6, 1121-1130. doi: 10. 1039/c8en01418c

Yoo, D., Park, Y., Cheon, B., and Park, M. H. (2019). Carbon dots as an effective fluorescent sensing platform for metal ion detection. Nanoscale Res Lett. 14:272. doi: 10.1186/s11671-019-3088-6

Zhang, C., Wu, S., Yu, Y., and Chen, F. (2020). Determination of thiourea based on the reversion of fluorescence quenching of nitrogen doped carbon dots by Hg2+. Spectrochim. Acta Part A Mol. Biomol. Spectrosc. 227:117666. doi: 10.1016/j.saa.2019.117666

Zhang, H., You, J., Wang, J., Dong, X., Guan, R., and Cao, D. (2020). Highly luminescent carbon dots as temperature sensors and "off-on" sensing of $\mathrm{Hg} 2+$ and biothiols. Dyes Pigm. 173:107950. doi: 10.1016/j.dyepig.2019.107950

Zhang, X., Jiang, M., Niu, N., Chen, Z., Li, S., Liu, S., et al. (2018). Naturalproduct-derived carbon dots: from natural products to functional materials. ChemSusChem 11, 11-24. doi: 10.1002/cssc.201701847

Zhou, Y., Desserre, A., Sharma, S. K., Li, S., Marksberry, M. H., Chusuei, C. C., et al. (2017). Gel-like carbon dots: characterization and their potential applications. ChemPhysChem 18, 890-897. doi: 10.1002/cphc.201700038

Zhou, Y., Mintz, K. J., Sharma, S. K., and Leblanc, R. M. (2019). Carbon dots: diverse preparation, application, and perspective in surface chemistry. Langmuir 35, 9115-9132. doi: 10.1021/acs.langmuir.9b00595

Zulfajri, M., Abdelhamid, H. N., Sudewi, S., Dayalan, S., Rasool, A., Habib, A., et al. (2020). Plant part-derived carbon dots for biosensing. Biosensors 10:68. doi: 10.3390/bios 10060068

Conflict of Interest: The authors declare that the research was conducted in the absence of any commercial or financial relationships that could be construed as a potential conflict of interest.

Copyright (C) 2021 Huang, Ge, Ren, Huang, Xu and Wang. This is an open-access article distributed under the terms of the Creative Commons Attribution License (CC BY). The use, distribution or reproduction in other forums is permitted, provided the original author(s) and the copyright owner(s) are credited and that the original publication in this journal is cited, in accordance with accepted academic practice. No use, distribution or reproduction is permitted which does not comply with these terms. 